\title{
Investigation of the antidepressant effects of exopolysaccharides obtained from Marasmius androsaceus fermentation in a mouse model
}

\author{
JIA SONG ${ }^{1,2}$, GAOYANG XING ${ }^{1}$, JIAMING CAO ${ }^{1}$, LIRONG TENG ${ }^{1}$, CHENLIANG LI $^{1}$, QINGFAN MENG ${ }^{1}$, \\ JIAHUI LU ${ }^{1}$, YULIN ZHOU ${ }^{1}$, YANG LIU ${ }^{1}$, DI WANG ${ }^{1,3}$ and LESHENG TENG ${ }^{1,3}$ \\ ${ }^{1}$ School of Life Sciences, Jilin University, Changchun, Jilin 130012; ${ }^{2}$ College of Biotechnology, \\ Tianjin University of Science and Technology, Tianjin 300457; ${ }^{3}$ The State Engineering Laboratory of AIDS Vaccine, \\ Jilin University, Changchun, Jilin 130012, P.R. China
}

Received January 17, 2015; Accepted October 28, 2015

DOI: $10.3892 / \mathrm{mmr} .2015 .4584$

\begin{abstract}
Marasmius androsaceus, a well-known medical fungus, possesses antihypertensive, analgesic and antioxidant effects. Exopolysaccharide (EPS), produced by microorganism secretion, exerts various types of biological activities. The present study aimed to investigate the antidepressant-like effect of the EPS produced during Marasmius androsaceus submerge fermentation (MEPS). Based on the assessment of acute toxicity and behavior, a forced swimming test (FST), tail suspension test (TST), 5-hydroxytryptophan-induced head-twitch assessment and reserpine-induced hypothermia assessment were performed. The administration of MEPS for 7 days enhanced mouse locomotor and balance ability in the mice. Similar to the results following treatment with fluoxetine, which was used as positive control drug, MEPS significantly decreased the duration of immobility in the FST and TST, increased head twitches in the 5-HTP-induced head-twitch test and enhanced rectal temperature in resperpine-induced hypothermia. MEPS altered the abnormal concentrations of 5-hydroxytryptamine, 5-hydroxyindoleacetic acid, dopamine and norepinephrine in the hypothalamus in the resperine-induced mouse model. Additionally, an increase in the expression of tyrosine hydroxylase and a reduction in the level of dopamine transporter in the hypothalamus were noted following 7 days of MEPS administration. Taken together, the EPS produced during MEPS exhibited antidepressant-like effects, which may be associated with its regulation on the dopaminergic system. The results of the present study provide
\end{abstract}

Correspondence to: Professor Di Wang or Dr Lesheng Teng, School of Life Sciences, Jilin University, 2699 Qianjin Avenue, Changchun, Jilin 130012, P.R. China

E-mail: jluwangdi@gmail.com

E-mail: tenglesheng@jlu.edu.cn

Key words: Marasmius androsaceus, 5-hydroxytryptamine, dopamine, exopolysaccharide, antidepressant experimental evidence supporting the clinical use of MEPS as an effective agent against depression.

\section{Introduction}

Patients suffering from depression present with dysfunctions in brain morphology and activity $(1,2)$. Due to its relatively high lifetime prevalence and substantial associated disability, depression is considered a worldwide problem in humans $(1,2)$. According to statistics, depression affects almost $15-25 \%$ of the world's population, and is expected to become the second largest global burden by 2020 (3). According to the monoamine hypothesis, depression is interrelated with the metabolic turnover of dopamine (DA) in the hippocampus, and/or serotonin (5-hydroxytryptamine; 5-HT) in the prefrontal cortex and striatum in rat brains (4). In addition, serotonin transporter, dopamine transporter (DAT) and tyrosine hydroxylase (TH) are important in antidepressants (5). The four types of antidepressant drugs, selective serotonin re-uptake inhibitors (SSRIs), tricyclic antidepressants, serotonin-noradrenergic re-uptake inhibitors and monoamine oxidase inhibitors, are commonly used in clinical treatment $(6,7)$. However, each of these drugs exhibit various adverse effects, with high relapse rates and a long onset of therapeutic action (8). Due to the limited using of existing antidepressant drugs, the development of novel alternative therapies is in high demand (9).

Herbal medicine have become a valuable reservoir for novel drugs due their limited side effects (9). The use of Traditional Chinese medicine has been confirmed to be an effective alterative in treating depression. Acanthopanax senticosus possesses antidepressant-like effects and has beneficial effects in patients with depression (10). Studies have suggested that Areca catechu fruit extract exerts antidepressant activities in an animal model (11). Wuling capsule, produced by Wuling submerged fermentation mycelium, has also been used as an antidepressant agent for clinical use in China $(12,13)$. Marasmius androsaceus, a well-known medical fungus, possesses antihypertensive, analgesic and antioxidant properties $(14,15)$. In China, 'An-Luo Tong', which is produced from the fermented mycelium of Marasmius androsaceus, has been 
used as a painkiller for $\sim 10$ years (16). However, the regulatory effects of Marasmius androsaceus by-products following its submerged fermentation on depressant-like effects in mice remain to be elucidated.

Exopolysaccharide (EPS) is produced from microorganism secretion and can be readily separated from bacteria. Compared with plant polysaccharides, EPS has the advantage of efficient production duration, convenient extraction and the absence of geographical restrictions (17). Investigations on the various types of biological activity of EPS have revealed antioxidant effects (18) and enhanced immunity (19). The EPS produced by Cordycept militaris has an antihyperglycemic effect in diabetic mice induced by streptozotocoin injection (20), and EPS separated from Morchella conica markedly prolongs the life-span of fruit flies (21).

Therefore, the present study hypothesized that The EPS produced during Marasmius androsaceus submerge fermentation may possess antidepressant effects. To test this hypothesis, the present study aimed to investigate the associated biological activities of Marasmius androsaceus EPS (MEPS) using a mouse model. The effects of MEPS were analyzed by performing a mouse forced swimming test (FST) and tail suspension test (TST), and changes in the concentrations of monoamine neurotransmitters, including DA, norepinephrine (NE), 5-HT and 5-hydroxyindoleacetic acid (5-HIAA) in the hypothalamus were detected. To further analyze its underlying mechanism, the expression levels of DAT and TH in the hypothalamus were detected using western blot analysis. The resulting data may provide experimental evidence supporting the clinical use of Marasmius androsaceus exopolysaccharide as an effective agent against depression.

\section{Materials and methods}

Submerged fermentation of Marasmius androsaceus. Marasmius androsaceus (CCTCC M2013175; China Center for Type Culture Collection, Wuhan, China) was cultured in a 100 liter fully-automatic fermentor (BaoXing Bioscience Company, Shanghai, China) using a defined liquid medium, containing $20 \mathrm{~g} / 1$ sucrose, $10 \mathrm{~g} / 1$ peptone, $10 \mathrm{~g} / 1$ yeast extract powder, $1 \mathrm{~g} / 1 \mathrm{MgSO}_{4} \cdot 7 \mathrm{H}_{2} \mathrm{O}, 1 \mathrm{~g} / 1 \mathrm{KH}_{2} \mathrm{PO}_{4} \cdot 3 \mathrm{H}_{2} \mathrm{O}$, and $0.1 \mathrm{~g} / \mathrm{l}$ vitamin $\mathrm{B}_{1}$. The fermentation conditions were as follows: Initial $\mathrm{pH}$ 6.5; rotation speed, $300 \mathrm{rpm}$; culture duration, 6 days; culture temperature, $26^{\circ} \mathrm{C}$; inoculum volume, $5 \%$; ventilation volume, $200 \mathrm{l} / \mathrm{h}$; inoculum age, 4 days; loading volume, 70/100 liters. All chemical reagents used in submerged fermentation were obtained from Sigma-Aldrich (St. Louis, MO, USA).

Sample preparation. The fermentation products were filtered using 120 mesh sifters and centrifuged at 4,500 $\mathrm{xg}$ for $10 \mathrm{~min}$. Using Sevag reagent (chloroform: n-butyl alcohol, 4:1), the existing proteins were extracted (22). A four-fold volume anhydrous ethanol was added for $12 \mathrm{~h}$ at $4^{\circ} \mathrm{C}$ to precipitate the crude EPS. Following $30 \mathrm{~min}$ centrifugation at 4,500 $\mathrm{x}$ g, the precipitate was washed with anhydrous ethanol and acetone (Sigma-Aldrich) three times. Following dialyzing, the crude EPS was lyophilized using a vacuum freeze dryer (GENESIS SQ 25ES; SP Industries Inc., Warminster, PA, USA) with primary drying at $60 \mathrm{mT}$ vacuum and a shelf temperature set at $-25^{\circ} \mathrm{C}$ for $10 \mathrm{~h}$. Prior to animal administration, the Marasmius androsaceus EPS (MEPS) and fluoxetine hydrochloride capsules (Shanghai Zhongxi Pharmaceutical Group Co., Ltd, Shanghai, China) were dissolved in physiological saline to $1 \mathrm{mg} / \mathrm{ml}$.

Animals and animal care. The experimental protocol used in the present study was approved by the ethics committee of the School of Life Sciences, Jilin University (Changchun, China). KunMing (KM) mice (6-week-old; 20-22 g; 1:1 male:female ratio) were housed in clear plastic cages and maintained in a $12 \mathrm{~h}$ light/dark cycle (lights on 7:00-19:00 h) at $23 \pm 1^{\circ} \mathrm{C}$, with water and food available ad libitum. At 8 hours prior to the experiment, the animals were deprived of food, but had free access to water. All experiments were performed in a quiet room, and each animal was assessed only once.

Acute toxicity assessment. The KM mice (6-week-old; 20-22 g; $n=20 /$ dosing group) were treated with MEPS at different concentrations $(0.1,1.0,2.0,4.0$ and $6.0 \mathrm{~g} / \mathrm{kg}$ ) via gavage for a period of 7 days. In a separate group, the mice were treated with equal volumes of normal saline, which served as a control group. The body weights of the mice were measured prior to administration and on day 7 . The animal were maintained under surveillance every day to record any adverse symptoms.

FST. Following MEPS treatment, an FST was used, in a similar manner to that described in a previous study with minor modifications (23). Briefly, the mice ( $n=10 /$ group) were orally administered with distilled water (vehicle), MEPS $(10,50$ or $250 \mathrm{mg} / \mathrm{kg})$ or fluoxetine $(10 \mathrm{mg} / \mathrm{kg})$ for 1 week, respectively. At $30 \mathrm{~min}$ following the final administration, the FST was performed. The mice were placed in an open cylindrical container $(30 \times 18 \mathrm{~cm})$ with a $15 \mathrm{~cm}$ depth, which did not permit the animal failed to touch the bottom of the cylinder. The water placed in the container was at a temperature of $24 \pm 1^{\circ} \mathrm{C}$. The duration of immobility was defined as the duration spent by the mouse floating in the water without struggling, and making only small movements necessary to maintain its head above the water. By using a stopwatch, the total duration of immobility was recorded in the final $5 \mathrm{~min}$ of a total duration of $6 \mathrm{~min}$. A decrease in the duration of immobility was considered to be a measurement of antidepressant activity.

TST. The TST was performed in a quiet experimental room, according to previous report (4). The mice ( $\mathrm{n}=10$ /group) were orally administered with either distilled water, MEPS (10, 50 or $250 \mathrm{mg} / \mathrm{kg})$ or fluoxetine $(10 \mathrm{mg} / \mathrm{kg})$ for 1 week, respectively. At 30 min following the final administration, the TST was performed. Each mouse was suspended by its tail to a horizontal wooden bar, which was located in a yellow plastic box $(40 \times 40 \times 40 \mathrm{~cm}), \sim 30 \mathrm{~cm}$ above the bottom. The mouse was secured to the bar by adhesive tape, which was placed $1 \mathrm{~cm}$ from the tip of tail so that its head was $\sim 20 \mathrm{~cm}$ above the floor. The trial was performed for 6 min, during which two observers scored the latency of the first immobility episode and the total duration of immobility using a stopwatch in a 
Table I. Analysis of body weights following treatment with MEPS to assess acute toxicity.

\begin{tabular}{|c|c|c|c|c|c|c|}
\hline \multirow[b]{2}{*}{ Day } & \multicolumn{6}{|c|}{ Body weights $(\mathrm{g})$ at different concentrations of MEPS $(\mathrm{g} / \mathrm{kg})$} \\
\hline & 0 & 0.1 & 1.0 & 2.0 & 4.0 & 6.0 \\
\hline 1 & $23.5 \pm 1.0$ & $23.8 \pm 0.9$ & $23.6 \pm 1.1$ & $23.4 \pm 0.8$ & $22.3 \pm 0.9$ & $23.2 \pm 1.6$ \\
\hline 2 & $24.6 \pm 1.8$ & $24.5 \pm 1.3$ & $24.7 \pm 1.2$ & $24.3 \pm 1.7$ & $25.0 \pm 0.8$ & $24.4 \pm 1.7$ \\
\hline 3 & $25.2 \pm 2.3$ & $24.7 \pm 1.8$ & $25.5 \pm 1.7$ & $26.0 \pm 1.4$ & $25.1 \pm 1.3$ & $24.5 \pm 1.7$ \\
\hline 4 & $26.1 \pm 1.9$ & $26.4 \pm 1.9$ & $25.7 \pm 1.7$ & $26.1 \pm 1.3$ & $25.2 \pm 1.3$ & $25.1 \pm 1.8$ \\
\hline 5 & $27.1 \pm 1.6$ & $27.1 \pm 2.3$ & $26.9 \pm 2.2$ & $27.3 \pm 1.6$ & $26.2 \pm 1.3$ & $25.6 \pm 1.9$ \\
\hline 6 & $27.9 \pm 2.1$ & $28.1 \pm 2.3$ & $27.6 \pm 2.4$ & $27.8 \pm 1.5$ & $27.3 \pm 1.7$ & $26.1 \pm 1.9$ \\
\hline 7 & $28.3 \pm 2.3$ & $28.4 \pm 1.7$ & $27.9 \pm 2.1$ & $28.3 \pm 1.7$ & $27.8 \pm 1.6$ & $26.6 \pm 1.6$ \\
\hline
\end{tabular}

Body weights were monitored every day. Data are expressed as the mean \pm standard error of the mean (n=20). MEPS, Marasmius androsaceus exopolysaccharide.

blinded-manner. The mouse was considered immobile only when it hung passively and completely motionless. Mice that climbed upwards grasping with its tail were eliminated from further analysis.

Behavioral assessment. With the purpose of excluding sedative or motor abnormality, the spontaneous locomotor activity was assessed (24). A clear acrylic chamber (11x11x15 cm), equipped with 12 infrared sensors for antomatic recording, was used. The mice ( $n=10 /$ group) were orally administered with either distilled water, MEPS $(10,50$ or $250 \mathrm{mg} / \mathrm{kg}$ ) or fluoxetine $(10 \mathrm{mg} / \mathrm{kg})$ for 1 week, respectively. At $30 \mathrm{~min}$ following the final administration, each mouse was initially placed in the center of the testing chamber. Following a 2-min period of adaptation, behavioral data Data associated with horizontal and vertical movements were collected and recorded for $5 \mathrm{~min}$.

To examine the coordination and balance of mouse movement, a rotation test was performed. The mice ( $n=10 /$ group) were orally administered with either distilled water, MEPS $(10,50$ or $250 \mathrm{mg} / \mathrm{kg})$ or fluoxetine $(10 \mathrm{mg} / \mathrm{kg})$ for 1 week, respectively. At $30 \mathrm{~min}$ following the last administration, the mice were placed on a fatigue turning device (ZB-200; Chengdu Taimeng Software, Co., Ltd., Chengdu, China). The rotation speed was maintained at $20 \mathrm{rpm}$. Prior to assessment, each mouse was trained three times and during the subsequent assessment a stopwatch was used to record the total duration each mouse spent on the rod prior to falling.

5-hydroxytryptophan (5-HTP)-induced head-twitch assessment. A 5-HTP-induced head-twitch assessment (25) was used to investigate whether serotonergic mechanisms were involved in the MEPS-mediated antidepressant-like effects. The mice ( $n=10 /$ group) were orally administered with either distilled water, MEPS $(10,50$ or $250 \mathrm{mg} / \mathrm{kg}$ ) or fluoxetine $(10 \mathrm{mg} / \mathrm{kg})$ for 1 week, respectively. At $30 \mathrm{~min}$ following the last administration, 5-HTP (100 mg/kg) was intraperitoneally administered to mice. Following administration, the mice were immediately placed into cages, and the cumulative number of head twitches during a 15 min period was recorded by two observers in a blinded-manner.
Reserpine-induced hypothermia assessment. The mice in each group, with the exception of the vehicle-treated control group, were injected intraperitoneally with $4.0 \mathrm{mg} / \mathrm{kg}$ reserpine $1 \mathrm{~h}$ following the 7-day MEPS (10,50 or $250 \mathrm{mg} / \mathrm{kg}$ ) and fluoxetine $(10 \mathrm{mg} / \mathrm{kg}$ ) treatments. After $2 \mathrm{~h}$, the rectal temperatures of the mice were determined. At the end of experiment, the mice were sacrificed by administration of $20 \mathrm{mg} / \mathrm{kg}$ pentobarbital, and the hypothalamus was collected. Tissue samples $(n=8)$ were homogenized with phosphate-buffered saline (PBS). Following centrifugation at $10,000 \times \mathrm{g}$ for $15 \mathrm{~min}$ at $4^{\circ} \mathrm{C}$, the level of monoamine neurotransmitters, including DA, NE, 5-HT and 5-HIAA, were detected using mouse ELISA kits for DA (cat. no. H170), 5-HT (cat. no. H104), NE (cat. no. H096) and 5-HIAA (cat. no. H104), from NanJing Biotechnology Co., Ltd. (NanJing, China). Briefly, $50 \mu 1$ of the horseradish peroxidase (HRP)-linked target solution and $50 \mu \mathrm{l}$ samples were added to the antibody-coated assay plate, which was incubated at room temperature for $1 \mathrm{~h}$ on a horizontal orbital plate shaker. The plate contents were then discarded and the wells were washed three times with $200 \mu \mathrm{l} /$ well of $1 \mathrm{X}$ wash buffer. The solution was discarded, and $100 \mu 1$ tetramethylbenzidine substrate was added to each well, and incubated for $10 \mathrm{~min}$ at room temperature. Following the addition of $100 \mu \mathrm{l}$ STOP solution, the absorbance was measured at $450 \mathrm{~nm}$ within 30 $\min$.

Western blot analysis. Sections of the collected hypothalamus samples were homogenized in radioimmunoprecipitation assay buffer (Sigma-Aldrich) containing 1\% protease inhibitor cocktail (Sigma-Aldrich) (26). Protein concentrations were determined using the Bradford method (27), and $30 \mu \mathrm{g}$ of the proteins were separated on an $10 \%$ SDS-PAGE gel and transferred electrophoretically onto nitrocellulose membranes (0.45 mm; Bio Basic, Inc., Markham, ON, Canada). The transferred membranes were blocked with $5 \%$ bovine serum albumin for $3 \mathrm{~h}$ at room temperature, followed by three washes with PBS. The membranes were then incubated with the following primary antibodies at $4^{\circ} \mathrm{C}$ overnight, at a dilution of 1:500: DAT (rabbit anti-rat monoclonal; cat. no. sc-32258; Santa Cruz Biotechnology, Inc., Dallas, TX, USA), TH (rabbit anti-rat monoclonal; cat. no. sc-14007 Santa Cruz 
A

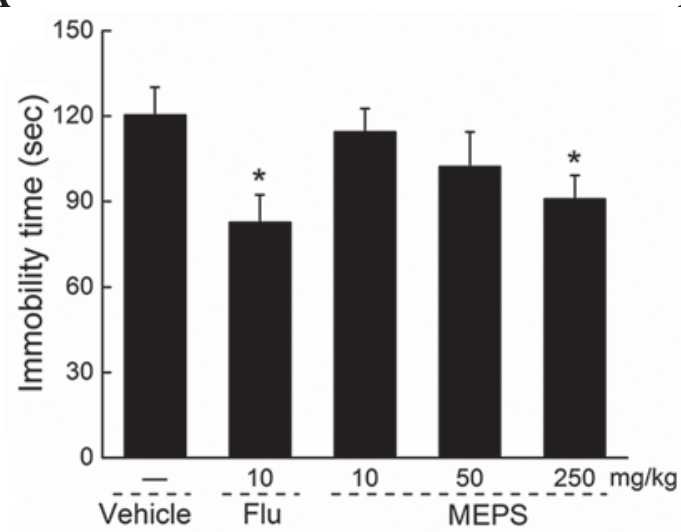

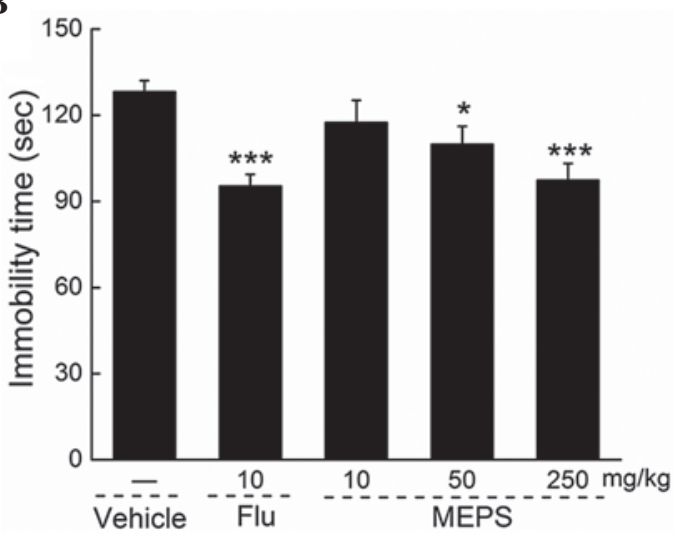

Figure 1. Effects of MEPS and Flu on the duration of immobility. The effects of MEPS (10,50 and $250 \mathrm{mg} / \mathrm{kg}$ ) or fluoxetine (10 mg/kg) on immobility duration were assessed in a (A) forced swimming test and (B) tail suspension test following treatment for 7 days. Data are expressed as the mean \pm standard error of the mean $(\mathrm{n}=20)$ and were analyzed using one-way analysis of variance followed by Dunn's test. ${ }^{*} \mathrm{P}<0.05$ and ${ }^{* * *} \mathrm{P}<0.001$, vs. vehicle group. MEPS, Marasmius exopolysaccharide; Flu, fluoxetine.

Biotechnology, Inc.) and GAPDH (rabbit anti-rat monoclonal; cat. no. ABS16 (Merck Millipore, Darmstadt, Germany), followed by treatment with horseradish peroxidase-conjugated secondary antibodies (mouse anti-rabbit monoclonal; cat. no. sc-2357; Santa Cruz Biotechnology, Inc.) for $4 \mathrm{~h}$ at $4^{\circ} \mathrm{C}$. Chemiluminescence was detected using ECL detection kits (GE Healthcare Life Sciences; Chalfont, UK). The intensity of the bands were quantified by scanning densitometry using Quantity One-4.5.0 software (Bio-Rad Laboratories, Inc., Hercules, CA, USA).

Statistical analysis. All values are expressed as the mean \pm standard error of the mean One-way analysis of variance was use to detect statistical significance, followed by post-hoc multiple comparisons (Dunn's test). SPSS 16.0 software (SPSS, Inc., Chicago, IL, USA) was used for statistical analyses. $\mathrm{P}<0.05$ was considered to indicate a statistically significant difference.

\section{Results}

Acute toxicity assessment of MEPS. Following 7 days of administration with MEPS $(0.1,1.0,2.0,4.0$ and $6.0 \mathrm{~g} / \mathrm{kg})$ via gavage, none of the mice in any groups succumbed to mortality. The mice maintained a suitable state of growth, and few adverse effects were noted. In addition, no significant differences in body weight were observed among the groups (Table I). These data suggested that, at the doses selected in the present study, MEPS was deemed a safe agent for further investigation.

Effects of MEPS on immobility duration in the FST and TST. Compared with the vehicle-treated mice, intrastral (i.g.) MEPS $(250 \mathrm{mg} / \mathrm{kg})$ and fluoxetine $(10 \mathrm{mg} / \mathrm{kg})$ administration significantly reduced immobility duration in the FST $(\mathrm{P}<0.05$; Fig. 1A). Similarly, MEPS (50 and $250 \mathrm{mg} / \mathrm{kg}$ and fluoxetine $(10 \mathrm{mg} / \mathrm{kg})$ treatment resulted in reductions in the duration of immobility in the TST $(\mathrm{P}<0.05$; Fig. 1B).

Effects of MEPS on animal behavior. Compared with the vehicle-treated group, the administration of MEPS at all the selected doses significantly increased locomotor ability, not only horizontally ( $\mathrm{P}<0.05$; Fig. $2 \mathrm{~A})$, but also vertically $(\mathrm{P}<0.05$; Fig. 2B). In addition, MEPS enhanced mouse coordination and balance, which was indicated by the increase in duration of retention on the Rota-Rod ( $\mathrm{P}<0.01$; Fig. $2 \mathrm{C}$ ).

Effects of MEPS in the 5-HTP-induced head-twitch assessment. To investigate the possible involvement of serotonergic mechanisms in MEPS-mediated antidepressant-like effects, a 5-HTP-induced head-twitch assessment was performed. MEPS $(250 \mathrm{mg} / \mathrm{kg})$ and fluoxetine $(10 \mathrm{mg} / \mathrm{kg})$ increased the number of head twitches by $\sim 56.27$ and $108.63 \%$, respectively, compared with the mice treated with 5-HTP (Sigma-Aldrich) alone ( $\mathrm{P}<0.05$; Fig. 3A). The administration of MEPS at lower doses of 10 and $50 \mathrm{mg} / \mathrm{kg}$ increased the numbers of head twitches by 21.88 and $39.92 \%$, respectively.

Effects of EPS on reserpine-induced hypothermia. The administration of $4.0 \mathrm{mg} / \mathrm{kg}$ reserpine significantly reduced rectal temperatures in the mouse model $(\mathrm{P}<0.001$; Fig. $3 \mathrm{~B})$. The administration of MEPS at doses of 50 and $250 \mathrm{mg} / \mathrm{kg}$, and of fluoxetine $(10 \mathrm{mg} / \mathrm{kg})$ significantly enhanced reserpine-reduced rectal temperature $(\mathrm{P}<0.001$; Fig. 3B), with an increment magnitude of $33.7 \%$ in the $50 \mathrm{mg} / \mathrm{kg}$ MEPS group, $35.5 \%$ in the $250 \mathrm{mg} / \mathrm{kg}$ MEPS group and $35.6 \%$ in the fluoxetine group, compared with the group treated with reserpine alone.

Effects of MEPS on neurotransmitters in reserpine-induced hypothermia. The levels of neurotransmitters in the hypothalamic tissues were detected in the reserpine-induced hypothermia mouse model. Reserpine at dose of $4.0 \mathrm{mg} / \mathrm{kg}$ significantly reduced the levels of 5-HT, DA and NE, compared with the vehicle group. By contrast, a significant increase in the concentration of 5-HIAA was observed ( $\mathrm{P}<0.05$; Fig. 4). Similar to the effects of fluoxetine $(10 \mathrm{mg} / \mathrm{kg})$ treatment, the administration of MEPS at a dose of $250 \mathrm{mg} / \mathrm{kg}$ markedly elevated the levels of 5-HT and DA, and reduced the increased levels of 5-HIAA, compared with the reserpine-only group $(\mathrm{P}<0.05$; Fig. 4A-C). Treatment with MEPS $(250 \mathrm{mg} / \mathrm{kg})$ for 7 days reversed the suppressive effect of reserpine on the level of NE (P<0.05; Fig. 4D). 

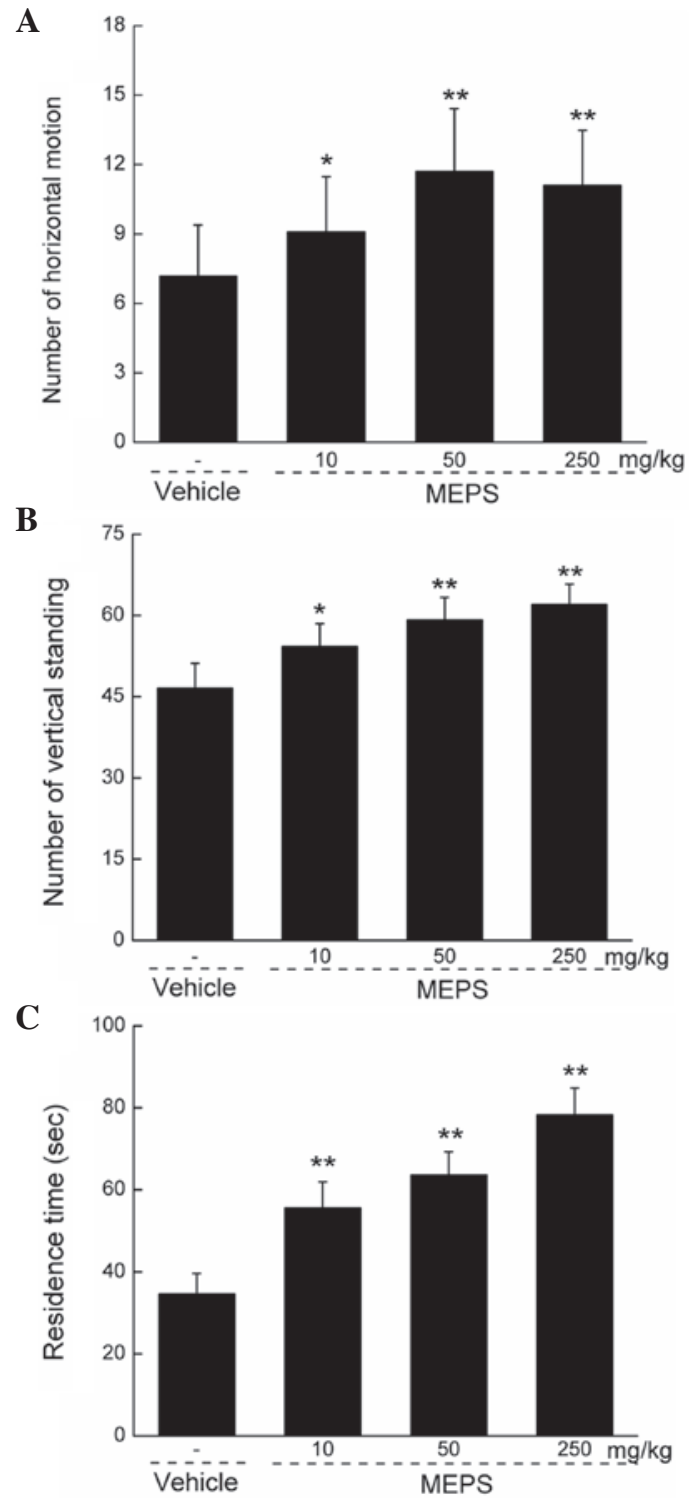

Figure 2. Effects of MEPS on animal behavior. The effects of treatment with MEPS $(10,50$ and $250 \mathrm{mg} / \mathrm{kg}$ ) on (A) spontaneous locomotor activity, (B) spontaneous standing and (C) residence time (duration of immobility) on a Rota rod were determined following 7 days treatment, respectively. Data are expressed as the mean \pm standard error of the mean $(n=10)$ and were analyzed using one-way analysis of variance followed by Dunn's test. ${ }^{*} \mathrm{P}<0.05$ and ${ }^{* *} \mathrm{P}<0.01$, vs. vehicle group. MEPS, Marasmius exopolysaccharide.

Effects of MEPS on the expression levels of DAT and TH in the hypothalamus. The expression levels of DAT and TH in the hypothalamus in the reserpine-induced hypothermia mouse model were also determined. Reserpine $(4.0 \mathrm{mg} / \mathrm{kg})$ injection resulted in a $37.57 \%$ reduction in the expression of $\mathrm{TH}$ in the hypothalamus, compared with the vehicle-treated group ( $\mathrm{P}<0.05$; Fig. 5$)$, however, no significant effect was detected in the level of DAT. Fluoxetine restored the abnormal expression of $\mathrm{TH}$ and increased the level of DAT $(\mathrm{P}<0.05$; Fig. 5). Similarly, MEPS at doses between 10 and $250 \mathrm{mg} / \mathrm{kg}$ significantly suppressed the levels of DAT, between $76.90 \pm 3.88$ and $50.43 \pm 5.51 \%(\mathrm{P}<0.05$; Fig. 5), compared with the reserpine-only group. MEPS treatment at 50 and $250 \mathrm{mg} / \mathrm{kg}$ for 7 days resulted in a 43.56 and $57.61 \%$ increase in the levels of $\mathrm{TH}$, respectively $(\mathrm{P}<0.05$; Fig. 5$)$.
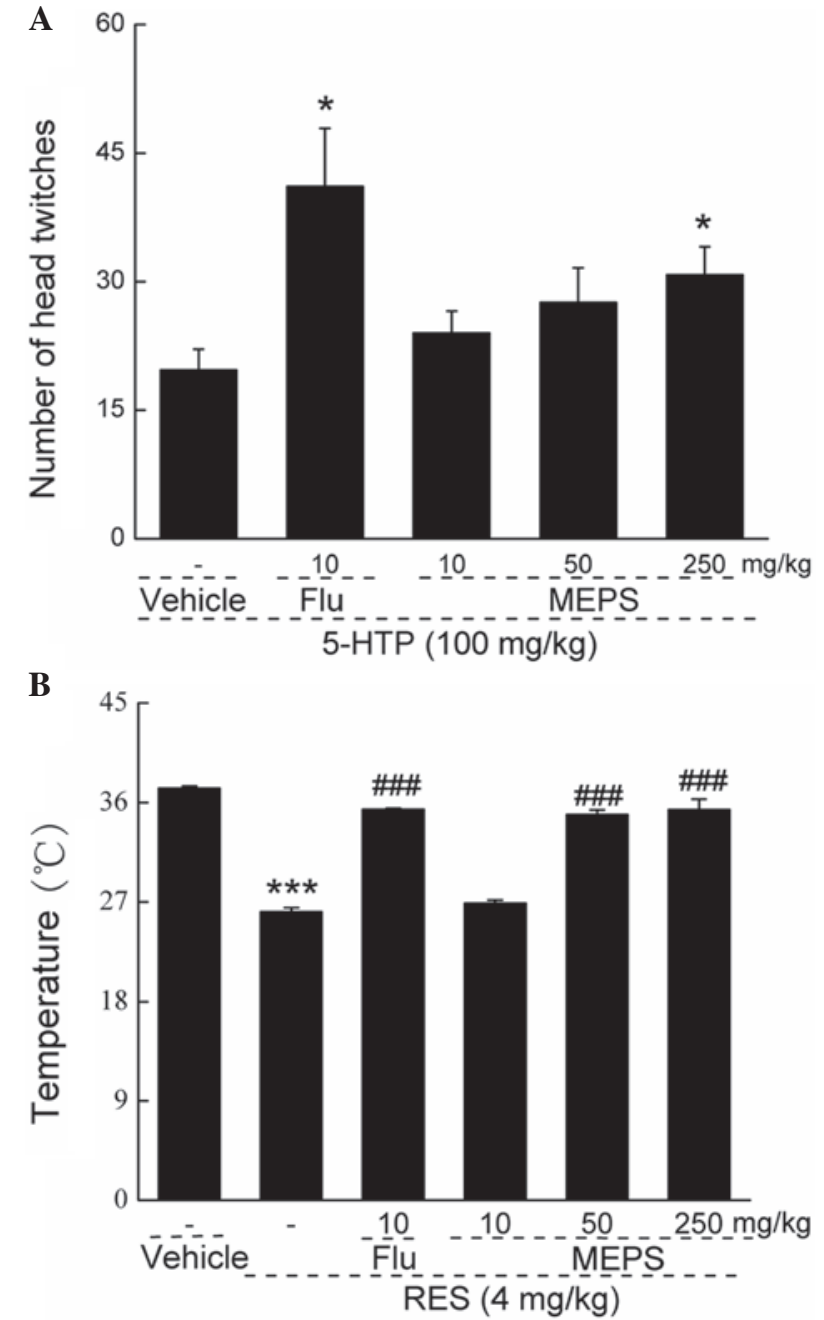

Figure 3. Effects of MEPS on RES-induced hypothermia. The administration of (A) Fluoxetine $(10 \mathrm{mg} / \mathrm{kg})$ and MEPS $(250 \mathrm{mg} / \mathrm{kg}$ ) for 7 days increased the number of head twitches on 5-HTP-induced head-twitch assessment. Rectal temperatures indicated that reatment with (B) fluoxetine $(10 \mathrm{mg} / \mathrm{kg})$ and EPS (50 and $250 \mathrm{mg} / \mathrm{kg}$ restored RES-induced hypothermia in the mouse model. Data are expressed as the mean \pm standard error of the mean $(n=10)$ and were analyzed using one-way analysis of variance followed by Dunn's test. ${ }^{\# \#} \mathrm{P}<0.001$, vs. RES alone; ${ }^{*} \mathrm{P}<0.05$, and ${ }^{* * *} \mathrm{P}<0.001$, vs. vehicle. 5 -HTP, MEPS, Marasmius exopolysaccharide; Flu, fluoxetine; RES, reserpine; 5-HT. 5-hydroxytryptamine.

\section{Discussion}

The safety of natural products has been an area of concern in the medical community and public (28). In the acute toxicity investigation performed in the present study, the highest non-toxic dose of MEPS selected for treatment of the male and female mice was $>20$-fold higher than its effective dose. Based on the results of the preliminary safety investigation, which revealed no significant adverse effects, the antidepressant-like effects of MEPS were assessed. Animal models of depression, including behavioral despair models (FST and TST) and drug-induced models (5-HTP-induced head-twitch assessment and antagonism of reserpine-induced hypothermia) are important in the scientific screening and evaluation of antidepressants (29,30). MEPS enhanced mouse locomotor activity following a 7-day administration period. In addition, $250 \mathrm{mg} / \mathrm{kg}$ MEPS treatment resulted in a reduction on the 

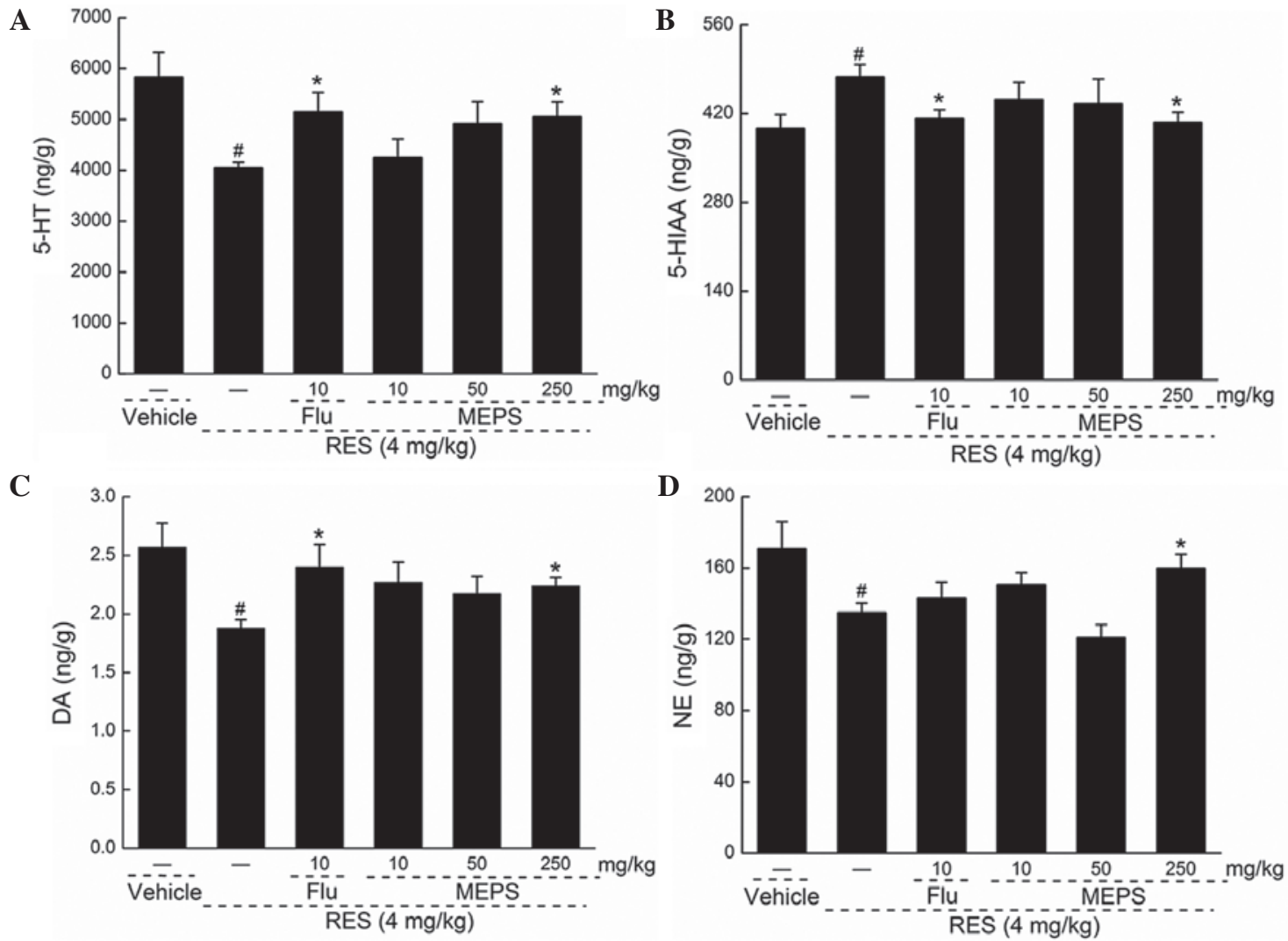

Figure 4. Effects of MEPS on neurotransmitters in reserpine-induced hypothermia. Following administration of MEPS (10, $50 \mathrm{and} 250 \mathrm{mg} / \mathrm{kg}$.) or fluoxetine $(10 \mathrm{mg} / \mathrm{kg}$ ) for 7 days, $4.0 \mathrm{mg} / \mathrm{kg}$ reserpine was injected intraperitoneally. The levels of (A) 5-HT, (B) 5-HIAA, (C) DA and (D) NE in the mouse hypothalamus were measured. Data are expressed as the mean \pm standard error of the mean $(n=8)$ and were analyzed using one-way analysis of variance. ${ }^{~} \mathrm{P}<0.05$, vs. vehicle; ${ }^{*} \mathrm{P}<0.05$ and $^{* *} \mathrm{P}<0.01$, vs. RES alone. MEPS, Marasmius exopolysaccharide; Flu, fluoxetine; RES, reserpine; 5-HT, 5-hydroxytryptamine; 5-HIAA 5-hydroxyindoleacetic acid; DA, dopamine; NE, norepinephrine.
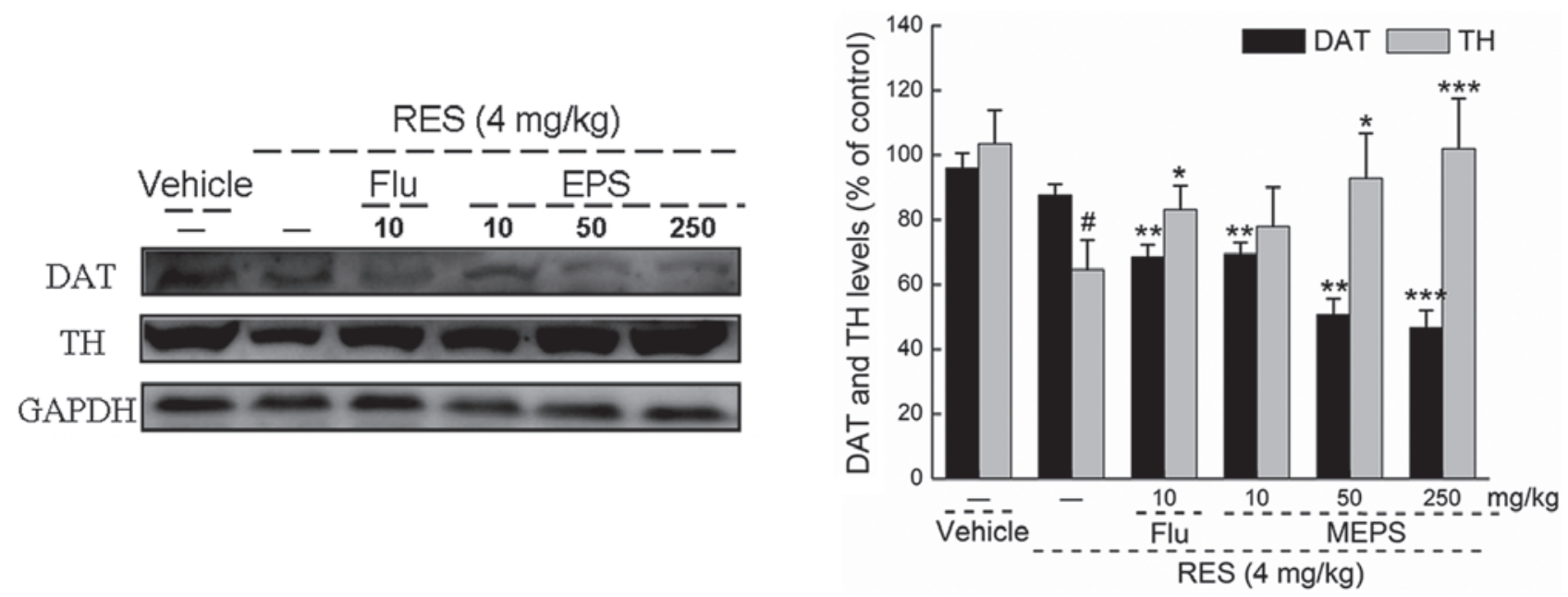

Figure 5. Effects of MEPS on the expression levels of DAT and TH in the hypothalamus. Following administration of MEPS (10,50 and $250 \mathrm{mg} / \mathrm{kg}$.) or fluoxetine $(10 \mathrm{mg} / \mathrm{kg})$ for 7 days, $4.0 \mathrm{mg} / \mathrm{kg}$ reserpine was injected intraperitoneally. The hypothalamus of the mice in each group were collected. Changes in the levels of TH and DAT in the hypothalamus were determined using western blot analysis. Quantifiied data were normalized by GAPDH, respectively. Data are expressed as the mean \pm standard error of the mean $(n=8)$ and were analyzed using one-way analysis of variance. ${ }^{~} \mathrm{P}<0.05$, vs vehicle; ${ }^{*} \mathrm{P}<0.05$, ${ }^{* *} \mathrm{P}<0.01$ and ${ }^{* * * *} \mathrm{P}<0.001$, vs. RES alone. MEPS, Marasmius exopolysaccharide; Flu, fluoxetine; RES, reserpine; DAT, dopamine transporter; TH, tyrosine hydroxylase.

duration of immobility in the FST and TST, suggesting its antidepressant activities. The 5-HTP-induced head-twitch and reserpine-induced hypothermia assessments were also used to confirm its effects.
As reported previously, SSRIs, including fluoxetine and paroxetine, can reduce immobility and increase swimming duration without affecting climbing (31). By contrast, selective NE or DA reuptake inhibitors, including desipramine or 
maprotiline, reduce immobility and increase climbing, without altering swimming (32). In the FST and TST performed in the present study, no swimming or climbing durations were recorded, therefore, additional experiments are required to determine whether MEPS regulates the 5-HT system, the dopaminergic system or both.

5-HT receptor agonists induce a characteristic head-twitch response, the frequency of which is dose-dependent (33). Due to it is ease of quantification, this response provides an attractive animal model for the investigation of transmitter interactions with 5-HTergic mechanisms (34). 5-HTP is one type of amino acid, which acts as a precursor of 5-HT (35). In the 5-HTP-induced head-twitch assessment performed in the present study, MEPS $(250 \mathrm{mg} / \mathrm{kg}$ ) significantly increased the number of head twitches $(\mathrm{P}<0.05)$. Furthermore, similar to the effects of fluoxetine, MEPS administration enhanced the concentration of 5-HT in the hypothalamus. However, the present study did not determine the changes in the expression levels of 5-HT receptors in the mouse model. A previous clinical study suggested that platelet 5 -HT content may serve as a supplementary biomarker for the function of uptake-associated mediators, including 5- $\mathrm{HT}_{1 \mathrm{~A}}$ receptors, in drug-free depressed patients (36). Numerous studies involving animal models have confirmed that an increase in $5-\mathrm{HT}_{1 \mathrm{~A}}$ autoreceptor density in the dorsal raphe reduces and delays the therapeutic response to SSRIs $(37,38)$. However, based on the results of the present study, it is difficult to conclude whether the MEPS-mediated antidepressant activity was associated with its regulation of the 5-HT system.

Reserpine is involved in the consumption of NE and 5-HT; 5-HIAA is the metabolic end product of 5-HT, and DA is the premise compound of NE (30). Based on these considerations, the levels of 5-HT, 5-HIAA, DA and NE in the hypothalamus were determined in the reserpine-induced hypothermia mouse model in the present study. Unlike fluoxetine, MEPS not only normalized the levels of 5-HT, 5-HIAA and DA; but it also reduced the hyperexpression of NE. These data suggested that the dopaminergic system may be involved in its antidepressant-like effect. To further confirm this hypothesis, the expression levels of DAT and TH in the mouse brain were analyzed. Selective noradrenaline re-uptake inhibitors and DAT inhibitors are important clinical antidepressants (39). The inhibition of DAT is considered a major mechanism underlying the therapeutic benefits of antihyperactivity medications, smoking cessation and antidepressants $(40,41)$. In the present study, MEPS markedly suppressed the expression of DAT in the hypothalamus of the resperpine-treated group, indicating that MEPS exerted a similar effect as the DAT inhibitor. In addition, TH is reported to be an enzyme responsible for the catalysis of amino acid L-tyrosine into dihydroxyphenylalanine (42), which is the premise compound of DA, therefore, $\mathrm{TH}$ exerts a rate-limiting role for DA synthesis $(43,44)$. In the present study, MEPS dose-dependently enhanced the expression of TH in the hypothalamus, which was consistent with the increase in the level of DA. Studies reporting results, which are consistent with the monoamine hypothesis have indicated that the majority of patients with depression have a deficit in brain DA and/or DA metabolites (45), and by increasing the expression levels of DA receptors or DA, the antidepressant enhances DA function (46).
Taken together, the results of the present study demonstrated that EPS produced during Marasmius androsaceus submerge fermentation exerts antidepressant-like effects, confirmed through use of a FWT, TST, 5-HTP-induced head-twitch assessment and reserpine-induced hypothermia assessment. MEPS regulated the concentration of neurotransmitters in the mouse hypothalamus. In addition, following MEPS administration for 7 days, the expression of DAT was suppressed; whereas the level of TH was enhanced. These results provide experimental evidence supporting the potential clinical use of MEPS as an effective agent against depression.

\section{Acknowledgements}

This study was supported by the National Science and Technology Support Program of P.R. China (grant no. 2012BAL29B05), the Natural Science Foundation of China (grant no. 81402955) and the Science and Technology Key Project of Jilin Province (grant no. 20130201006ZY).

\section{References}

1. Réus GZ, Vieira FG, Abelaira HM, Michels M, Tomaz DB, dos Santos MA, Carlessi AS, Neotti MV, Matias BI, Luz JR, et al: MAPK signaling correlates with the antidepressant effects of ketamine. J Psychiatr Res 55: 15-21, 2014.

2. Kessler RC and Wang PS: The descriptive epidemiology of commonly occurring mental disorders in the United States. Ann Rev Public Health 29: 115-129, 2008.

3. Manji HK, Drevets WC and Charney DS: The cellular neurobiology of depression. Nat Med 7: 541-547, 2001.

4. Steru L, Chermat R, Thierry B and Simon P: The tail suspension test: A new method for screening antidepressants in mice. Psychopharmacology (Berl) 85: 367-370, 1985.

5. Komiya M, Takeuchi T and Harada E: Lemon oil vapor causes an anti-stress effect via modulating the 5-HT and DA activities in mice. Behav Brain Res 172: 240-249, 2006.

6. Ma Z, Ji W, Qu R, Wang M, Yang W, Zhan Z, Fu Q and Ma S: Metabonomic study on the antidepressant-like effects of banxia houpu decoction and its action mechanism. Evid Based Complement Alternat Med 2013: 213739, 2013.

7. Kang A, Hao H, Zheng X, Liang Y, Xie Y, Xie T, Dai C, Zhao Q, Wu X, Xie L and Wang G: Peripheral anti-inflammatory effects explain the ginsenosides paradox between poor brain distribution and anti-depression efficacy. $\mathrm{J}$ Neuroinflammation 8: 100, 2011.

8. Kennedy SH: A review of antidepressant treatments today. Eur Neuropsychopharm 16 (Suppl): S619-S623, 2006.

9. Novak M and Vetvicka V: Beta-glucans, history and the present: Immunomodulatory aspects and mechanisms of action. J Immunotoxicol 5: 47-57, 2008.

10. Jin L, Wu F, Li X, Li H, Du C, Jiang Q, You J, Li S and Xu Y: Anti-depressant effects of aqueous extract from Acanthopanax senticosus in mice. Phytother Res 27: 1829-1833, 2013.

11. Dar A, Khatoon S, Rahman G and Atta-Ur-Rahman: Anti-depressant activities of areca catechu fruit extract. Phytomedicine 4: 41-45, 1997.

12. Peng L, Zhang X, Kang DY, Liu XT and Hong Q: Effectiveness and safety of wuling capsule for post stroke depression: A systematic review. Complement Ther Med 22: 549-566, 2014.

13. Wang XJ, Li J, Zou QD and Jin L: Wuling capsule for climacteric patients with depression and anxiety state: A randomized, positive parallel controlled trial. Zhong Xi Yi Jie He Xue Bao 7: 1042-1046, 2009 (In Chinese).

14. Wang X, Liang QM, Li TT, Zhi R, Zhang N and Lu J: Study on extraction and anti-oxidation of Marasmius androsaceus mycelium polysaccharides. Food Sci Technol 12: 80-83, 2006.

15. Ye WF, Yang XT, Chen Y and Li QL: Long-time analgesic effect of Marasmius androsaceus in rats. Zhong yao yao li yu lin chuang 18: 19-21, 2002 (In Chinese). 
16. Gao Yang YX-1 and Xu Duo-Duo: Glycopeptide physicochemical properties and analgesic effect of Marasmius androsaceus. Changchun Zhong yi xue yuan xue bao 777-778, 2013 (In Chinese).

17. Kim SW, Hwang HJ, Xu CP, Sung JM, Choi JW and Yun JW: Optimization of submerged culture process for the production of mycelial biomass and exo-polysaccharides by Cordyceps militaris C738. J Appl Microbiol 94: 120-126, 2003.

18. Chen H, Yan M, Zhu J and Xu X: Enhancement of exo-polysaccharide production and antioxidant activity in submerged cultures of Inonotus obliquus by lignocellulose decomposition. J Ind Microbiol Biotechnol 38: 291-298, 2011.

19. Shih IL: Microbial exo-polysaccharides for biomedical applications. Mini Rev Med Chem 10: 1345-1355, 2010.

20. Sun Na-Xin YG-W and An Li-Guo: Anti-hyperglycemic activities of exopolysaccharides from Cordyceps militaris in diabetic mice induced by multiple low-dose streptozotocoin. Shipin Kexue (Beijing) 288-295, 2013 (In Chinese).

21. Lan Ying PZ-F, Zhang Song and Yang Xiao-Bing: The Influence of exopolysaccharide extract of Morchella conica on fruit Fly's life-span. Zhong guo shi yong jun bian ji bu 43-45, 2010 (In Chinese).

22. Yan H, Zhu D, Xu D, Wu J and Bian X: A study on Cordyceps militaris polysaccharide purification, composition and activity analysis. Afr J Biotechnol 7: 4004-4009, 2008.

23. Porsolt RD, Bertin A and Jalfre M: Behavioral despair in mice: A primary screening test for antidepressants. Arch Int Pharmacodyn Ther 229: 327-336, 1977.

24. Pesarico AP, Sampaio TB, Stangherlin EC, Mantovani AC, Zeni G and Nogueira CW: The antidepressant-like effect of 7-fluoro-1,3-diphenylisoquinoline-1-amine in the mouse forced swimming test is mediated by serotonergic and dopaminergic systems. Prog Neuropsychopharmacol Biol Psychiatry 54: 179-186, 2014.

25. Xiang H, Liu Y, Zhang B, Huang J, Li Y, Yang B, Huang Z, Xiang $\mathrm{F}$ and Zhang $\mathrm{H}$ : The antidepressant effects and mechanism of action of total saponins from the caudexes and leaves of Panax notoginseng in animal models of depression. Phytomedicine 18 : 731-738, 2011.

26. Yang CL, Chik SC, Li JC, Cheung BK and Lau AS: Identification of the bioactive constituent and its mechanisms of action in mediating the anti-inflammatory effects of black cohosh and related Cimicifuga species on human primary blood macrophages. J Med Chem 52: 6707-6715, 2009.

27. Noble JE and Bailey MJ: Quantitation of protein. Methods Enzymol 463: 73-95, 2009.

28. Gao L, Liu G, Kang J, Niu M, Wang Z, Wang H, Ma J and Wang X: Paclitaxel nanosuspensions coated with P-gp inhibitory surfactants: I. Acute toxicity and pharmacokinetics studies Colloids Surf B Biointerfaces 111: 277-281, 2013.

29. Willner P: The validity of animal models of depression. Psychopharmacology (Berl) 83: 1-16, 1984.

30. Gao S, Cui YL, Yu CQ, Wang QS and Zhang Y: Tetrandrine exerts antidepressant-like effects in animal models: Role of brain-derived neurotrophic factor. Behav Brain Res 238: 79-85, 2013.

31. Cryan JF and Lucki I: Antidepressant-like behavioral effects mediated by 5-Hydroxytryptamine (2C) receptors. J Pharmacol Exp Ther 295: 1120-1126, 2000.

32. Page ME, Detke MJ, Dalvi A, Kirby LG and Lucki I: Serotonergic mediation of the effects of fluoxetine, but not desipramine, in the rat forced swimming test. Psychopharmacology (Berl) 147: 162-167, 1999.
33. Handley SL and Singh L: Modulation of 5-hydroxytryptamine-induced head-twitch response by drugs acting at GABA and related receptors. Br J Pharmacol 86: 297-303, 1985.

34. Peroutka SJ, Lebovitz RM and Snyder SH: Two distinct central serotonin receptors with different physiological functions. Science 212: 827-829, 1981.

35. Fukuda K: 5-HTP hypothesis of schizophrenia. Med Hypotheses 82: 20-23, 2014.

36. Zhang ZJ, Wang D, Man SC, Ng R, McAlonan GM, Wong HK, Wong W, Lee J and Tan QR: Platelet 5-HT (1A) receptor correlates with major depressive disorder in drug-free patients. Prog Neuropsychopharmacol Biol Psychiatry 53: 74-79, 2014.

37. Gardier AM, Malagié I, Trillat AC, Jacquot C and Artigas F: Role of 5-HT1A autoreceptors in the mechanism of action of serotoninergic antidepressant drugs: Recent findings from in vivo microdialysis studies. Fundam Clin Pharmacol 10: 16-27, 1996.

38. Rainer Q, Nguyen HT, Quesseveur G, Gardier AM, David DJ and Guiard BP: Functional status of somatodendritic serotonin $1 \mathrm{~A}$ autoreceptor after long-term treatment with fluoxetine in a mouse model of anxiety/depression based on repeated corticosterone administration. Mol Pharmacol 81: 106-112, 2012.

39. Haenisch B and Bönisch H: Depression and antidepressants: Insights from knockout of dopamine, serotonin or noradrenaline re-uptake transporters. Pharmacol Ther 129: 352-368, 2011.

40. Tashkin DP, Rabinoff M, Noble EP, Ritchie TL, Simmons MS and Connett J: Association of dopamine-related gene alleles, smoking behavior and decline in FEV1 in subjects with COPD: findings from the lung health study. COPD 9: 620-628, 2012.

41. Madras BK, Fahey MA, Miller GM, De La Garza R, Goulet M, Spealman RD, Meltzer PC, George SR, O'Dowd BF, Bonab AA, et al: Non-amine-based dopamine transporter (reuptake) inhibitors retain properties of amine-based progenitors. Eur J Pharmacol 479: 41-51, 2003.

42. Cunha MP, Pazini FL, Oliveira Á, Bettio LE, Rosa JM, Machado DG and Rodrigues AL: The activation of $\alpha 1$-adrenoceptors is implicated in the antidepressant-like effect of creatine in the tail suspension test. Prog Neuropsychopharmacology Biol Psychiatry 44: 39-50, 2013.

43. Rovin ML, Boss-Williams KA, Alisch RS, Ritchie JC, Weinshenker D, West $\mathrm{CH}$ and Weiss JM: Influence of chronic administration of antidepressant drugs on mRNA for galanin, galanin receptors and tyrosine hydroxylase in catecholaminergic and serotonergic cell-body regions in rat brain. Neuropeptides 46: 81-91, 2012.

44. Nagatsu T, Levitt $M$ and Udenfriend S: Tyrosine Hydroxylase. The initial step in norepinephrine biosynthesis. J Biol Chem 239: 2910-2917, 1964.

45. Lambert G, Johansson M, Agren H and Friberg P: Reduced brain norepinephrine and dopamine release in treatment-refractory depressive illness: Evidence in support of the catecholamine hypothesis of mood disorders. Arch Gen Psychiatry 57: 787-793, 2000.

46. Ainsworth K, Smith SE, Zetterstrom TS, Pei Q, Franklin M and Sharp T: Effect of antidepressant drugs on dopamine D1 and D2 receptor expression and dopamine release in the nucleus accumbens of the rat. Psychopharmacology (Berl) 140: 470-477, 1998. 